\title{
REPRODUKSI SAPI PERAH FRIESIAN HOLSTEIN PADA BERBAGAI PERIODE LAKTASI
}

\author{
Reproductive Performance Friesian Holstein Cattle in Various Lactation Period
}

\author{
Ali Mahmud, Woro Busono, Puguh Surjowardojo \\ Faculty of Animal Husbandry, Brawijaya University \\ Veteran, Malang, East Java Province \\ Email : alimahmud.df@gmail.com
}

\begin{abstract}
The purpose of this research is to compare the efficiency of reproductive performance Friesian Holstein $(\mathrm{FH})$ in various lactation periods. The material used in this research is obtained from the records of reproductive performance Friesian Holstein (FH) cattle from Australia and has been developed in PT. Greenfield Indonesia farm. Datas were using 473 heads dairy cattle these were 100 heads for each lactation period I up to IV and 73 heads for lactation period $V$. The variable measured were efficiency of reproductive include service per conception $(S / C)$; days open $(D O)$ and calving interval $(C I)$. The datas were analyzed using Completely Randomize Design one-way analyzes of variance (one way lay out) and if the result showed differences, the research will be continued using Least Significant Difference (LSD). The results showed that the higher lactation period of dairy cattle the greater the $S / C, D O$ and $C I(P<0.01)$. In lactation period I and II earned S/C value 2.6 \pm 1.3 and 2.1 \pm 1.1 were lower than lactation period III, IV and $V$ which

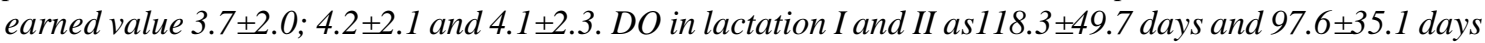
were lower than lactation period III, IV, and $V$ is $153.5 \pm 65.8$ days; $168.2 \pm 81.5$ days and $59.2 \pm 74.7$ days. The lower CI was in period lactation II 365.8 36.9 days compared with lactation period III, IV and V as $393.8 \pm 54.5$ days; $406.1 \pm 78.3$ days and $401.3 \pm 65.1$ days. Conclusion of this research was lactation period has an effect on the performance of FH dairy reproduction, the higher of lactation period would increase $S / C, D O$ and $C I$.
\end{abstract}

Keywords : Calving Interval, Days Open, Friesian Holstein Cattle, Lactation Period, Service Per Conception.

\section{PENDAHULUAN}

Evaluasi penampilan reproduksi pada sapi perah Friesian Holland (FH) sangat penting dilakukan untuk meningkatkan produksi susu. Efisiensi reproduksi dipengaruhi oleh faktor internal dan faktor eksternal. Faktor internal antara lain umur sapi dan periode laktasi serta faktor eksternal antara lain tatalaksana pemeliharaan dan kondisi iklim. roduksi susu pada sapi FH dapat ditingkatkan dengan cara meningkatkan efisiensi reproduksi. Parameter yang sering digunakan untuk mengetahui efisiensi reproduksi adalah umur kawin pertama, umur beranak pertama, interval kawin pertama setelah beranak, service per conception $(S / C)$, interval kawin pertama sampai terjadi kebuntingan, masa kosong/days open (DO), masa bunting dan selang beranak/calving interval (CI).

Periode laktasi berkaitan dengan umur sapi perah saat beranak pertama atau laktasi pertama menentukan jumlah produksi susu yang dihasilkan pada periode laktasi tersebut, begitu juga jumlah produksi susu selama sapi perah tersebut hidup. Soeharsono (2008) mengemukakan bahwa secara umum kapasitas produksi susu berbeda pada setiap periode laktasi. Periode laktasi memiliki peranan yang cukup penting karena berkaitan dengan umur seekor ternak misalnya umur pertama kali beranak sangat mempengaruhi produktivitas ternak tersebut (Purba, 2008). Periode laktasi ternak atau periode laktasi menunjukkan berapa kali ternak tersebut telah mengalami partus.

Periode laktasi memiliki peranan yang cukup penting karena berkaitan dengan umur seekor ternak misalnya umur pertama kali beranak sangat mempengaruhi produktivitas ternak tersebut (Purba, 2008). Pertambahan nilai periode laktasi cenderung menyebabkan penurunan efisensi reproduksi dan jumlah produksi susu. Faktor fisiologi antara lain penurunan fungsi otot, penurunan fungsi kelenjar ambing, penurunan kemampuan mencerna makanan dan kerusakan sel-sel di dalam tubuh akibat bertambahnya umur diduga menjadi 
penyebab penurunan produksi susu (Zainudin et al. 2015).

Berdasarkan uraian diatas maka dilakukan penelitian untuk mengetahui pengaruh periode laktasi terhadap performans reproduksi sapi perah di PT. Greenfields Indonesia sehingga dapat bermanfaat bagi peternak dan industri peternakan sapi perah serta para pengguna yang memerlukan informasi mengenai periode laktasi dan performans reproduksi pada sapi perah $\mathrm{FH}$ untuk mendapatkan produktivitas yang optimal.

\section{MATERI DAN METODE}

Penelitian dilaksanakan di PT. Greenfields Indonesia di Desa Babadan Kecamatan Ngajum Kabupaten Malang, pada bulan Mei sampai dengan Juni 2017. Materi yang digunakan dalam penelitian ini catatan reproduksi dan produksi susu dari sapi perah $\mathrm{FH}$ yang didatangkan dari Australia dan telah dikembangkan di peternakan PT. Greenfields Indonesia. Data yang digunakan merupakan data primer 473 ekor sapi perah dengan rincian jumlah sapi dengan periode Laktasi I - IV masing-masing sebanyak 100 ekor dan sapi Laktasi V sebanyak 73 ekor. Penentuan sampel menggunakan purposive sampling. Variabel yang diamati adalah efisiensi reproduksi dan produksi susu pada sapi perah yang terdiri atas S/C, DO dan CI. Untuk membandingkan periode laktasi terhadap efisiensi reproduksi pada sapi perah digunakan analisis ragam/analysis of variance (ANOVA one way lay out) dan apabila menunjukkan perbedaan, maka dilanjutkan dengan uji Beda Nyata Terkecil (BNT) (Steel and Torie, 2003).

\section{HASIL DAN PEMBAHASAN}

Reproduksi merupakan faktor penting yang dapat mempengarui efisiensi reproduksi dari suatu ternak betina. Efisiensi reproduksi dikatakan baik apabila seekor Induk sapi dapat menghasilkan satu pedet dalam satu tahun (Ball and Peters, 2007). Hasil pengamatan S/C, DO dan CI di penelitian terdapat pada sifat reproduksi sapi perah disajikan pada Tabel 1 .

Hasil analisis ragam menunjukan bahwa periode laktasi berpengaruh sangat nyata $(\mathrm{P}<0,01)$ terhadap nilai $\mathrm{S} / \mathrm{C}, \mathrm{DO}$ dan CI pada sapi perah. Hasil pengamatan menunjukan nilai $\mathrm{S} / \mathrm{C}$ semakin meningkat seiring meningkatnya periode laktasi. Meningkatnya nilai S/C pada sapi perah berkaitan dengan umur ternak dimana semakin muda umur sapi perah maka nilainya semakin baik karena berkaitan dengan sistem reproduksi ternak yang masih baik.
Hasil rataan menunjukan semakin tinggi periode laktasi sapi perah maka nilai S/C nya semakin besar pula dimana pada periode laktasi I diperoleh nilai S/C sebesar 2,6 $\pm 1,3$ kemudian turun pada periode laktasi ke dua sebesar 2,1 1 ,1 dan kemudian naik lagi dengan nilai terbesar pada periode laktasi IV dengan nilai $4,2 \pm 2,1$. Nilai S/C yang rendah pada periode laktasi II diduga karena ternak sapi perah sudah mengalami kematangan reproduksi dimana umur sapi berkisar 3 tahun. Nilai S/C sapi FH untuk beberapa daerah di pulau Jawa memperlihatkan nilai lebih dari 2,0. Sapi FH semua periode laktasi yang dipelihara di PT. Greenfields Indonesia akan mengalami cekaman panas sepanjang tahun. Sapi FH tersebut mengalami nilai S/C yang semakin tinggi pada keturunannya. Kondisi lingkungan sekitar terutama suhu dan kelembaban menyebabkan kenaikan S/C pada pada sapi FH generasi keturunan di lokasi penelitian. Menurut Ray et al. (1992) musim panas (summer) di daerah temperate meningkatkan S/C yaitu 1.93 dibandingkan musim semi (spring) 1.54 dan 1.81 pada musim gugur (fall). Rataan S/C pada setiap periode laktasi mengalami penurunan dari periode laktasi I $(2,62)$ sampai periode laktasi ke II (2.14) dan kemudian terjadi kenaikan angka S/C pada periode laktasi ke III, ke IV dan ke V.

Nilai S/C yang rendah diartikan dengan kesuburan hewan betina yang semakin tinggi, sebaliknya jika nilai S/C yang tinggi diartikan dengan kesuburan hewan betina yang semakin rendah. Pada sapi perah induk dalam hubungannya dengan panjang laktasi, S/C diharapkan adalah 2 dan tidak lebih dan tidak kurang. Sebab dengan S/C sama dengan 2 dan mulai di IB sekitar 60 hari setelah beranak, maka akan mencapai masa kosong sekitar 81-85 hari. Masa kosong dengan kisaran tersebut akan dapat mencapai panjang laktasi yang optimal yakni sekitar 305 hari.

Days Open atau lama kosong tertinggi pada penelitian ini terdapat pada sapi perah periode laktasi IV sebesar $168,2 \pm 81,5$ hari tetapi tidak berbeda dengan periode laktasi III dan V dan terendah pada pada periode laktasi II sebesar $97,6 \pm 35,1$ hari. Rendahnya DO pada periode laktasi II disebabkan karena nilai S/C pada periode laktasi ini juga rendah sehingga mempengaruhi nilai DO. Hasil tersebut dapat dinyatakan hari kosong sapi perah di lokasi penelitian berada di atas rata-rata optimal 60-90 hari. Hari kosong yang panjang pada sapi perah disebabkan S/C rendah yang disebabkan beberapa hal diantaranya adalah umur ternak yang berkaitan dengan periode laktasi dan iklim dimana ternak sapi yang dipelihara merupakan 
sapi perah FH murni yang berasal dari Australia sehingga belum beradaptasi dengan baik dalam lingkungan Indonesia walaupun secara manajemen sudah dilaksanakan dengan baik sehingga mempengaruhi birahi ternak dan periode laktasi yang berkaitan dengan umur.

Sapi FH mengalami penurunan masa kosong dengan bertambahnya usia atau bertambah periode laktasi tetapi setelah periode laktasi ke enam mulai tidak teratur. Sapi FH akan bertambah besar badannya dengan bertambahnya umur sampai dengan berumur 7 tahun. Masa kosong akan berkurang dengan bertambahnya umur atau periode laktasi karena berhubungan dengan peningkatan kemampuan fisioligis tubuh, khususnya peningkatan fisiologis saluran reproduksinya. Sapi FH pada lokasi penelitian mempunyai masa kosong lebih lama dari laporan Effendi et al. (2002) yaitu masa kosong 80 hari pada laktasi pertama dan 60 hari untuk laktasi berikutnya. Masa kosong dilokasi penelitian mempunyai pola yang sama dengan Effendi et al. (2002) tetapi berbeda dengan laporan Mitchell et al. (2005) serta Turkylenaz (2005). Masa kosong dilokasi penelitian memiliki pola grafik yang sama dengan interval dikawinkan kembali setelah beranak dan S/C, dimana masa kosong ialah akumulasi dari interval dikawinkan kembali setelah beranak dan S/C. Faktor penyebab panjang pendeknya masa kosong pada kedua lokasi ialah karena interval dari induk beranak sampai dikawinkan kembali. Namun nilai DO sapi perah pada lokasi penelitian apabila dibandingkan dengan masa kosong sapi FH di beberapa tempat lain seperti misalnya di Amerika memiliki kisaran 134-159 hari (Oseni et al., 2003) dan 186-284 di Filipina (Alejandrino et al., 1999). Menurut Lee et al. (2008) sapi-sapi FH yang mempunyai produksi susu lebih tinggi pada awal laktasi akan memiliki masa kosong lebih panjang. Peningkatan masa kosong akan mengurangi keuntungan karena biaya perkawinan akan naik, naiknya resiko sapi apkir dan biaya sapi pengganti dan mengurangi produksi susu (DeVriest, 2006), dan persentase kebuntingan menurun apabila masa kosong naik dari 122 ke 166 hari. Menururt Izquierdo et al. (2008) masa kosong dipengaruhi oleh banyak faktor diantaranya adalah jenis kelamin, dimana induk yang melahirkan anak jantan akan mempunyai masa kosong lebih pendek terhadap kelahiran anak betina. Dinyatakan bahwa untuk mencapai produksi susu yang efisien dapat dilakukan dengan mengurangi masa kosong.

Nilai calving interval tertinggi pada periode laktasi IV sebesar $406,1 \pm 78,3$ hari dan terendah sebesar $365,8 \pm 36,9$ hari yang terdapat pada sapi perah periode laktasi II. Rendahnya calving interval pada sapi perah periode laktasi II berkaitan dengan umur dan iklim. Panjang calving interval untuk sapi periode laktasi I; II; III; IV dan V berturut-turut adalah 0 hari; $365,8 \pm 36,9$ hari; $393,8 \pm 54,5$ hari; 406,1 $\pm 78,3$ hari dan 401,3 $\pm 65,1$ hari. Sapi-sapi FH di lokasi penelitian tersebut mengalami lama selang beranak yang semakin bertambah lama dengan bertambahnya umur ternak. Secara deskriptif memperlihatkan bahwa sapi FH di PT. Greenfields Indonesia mengalami penurunan atau semakin kurang efisien dari segi lama selang beranak dengan meningkatnya periode laktasi. Selang beranak dipengaruhi oleh masa kosong dan lama bunting. Masa kosong merupakan factor utama yang menyebabkan selang beranak yang panjang waktunya. Sapi FH periode laktasi IV dan V mempunyai masa kosong paling lama sehingga menyebabkan selang beranak paling lama.

Lama selang beranak untuk semua periode laktasi mempunyai nilai yang hampir sama dengan yang dianjurkan oleh para ahli. Menurut Sudono et al. (2005) dan Izqulerdo et al. (2008) lama selang beranak (calving interval) yang optimal untuk sapi perah adalah 12 - 13 bulan. Lama selang beranak yang dianjurkan adalah terdiri atas lama masa kosong 3 - 4 bulan dan lama masa bunting 9 bulan. Lama masa bunting pada sapi FH adalah sudah pasti sehingga yang akan diatur secara manajemen adalah pengaturan lama masa kosong.

Lama selang beranak untuk masingmasing periode laktasi mempunyai pola yang semakin meningkat sampai dengan laktasi ke IV dan ternyata mempunyai pola yang sama dengan lama masa kosongnya. Lama masa kosong pada penelitian ini mempunyai pola yang semakin menurun dari periode laktasi pertama $(118,33$ hari) ke periode laktasi II (97,67 hari) kemudian naik lagi sampai dengan periode laktasi ke V (159,29 hari). Sapi FH memerlukan perpendekan lama masa kosong untuk mengurangi lama masa kosong dengan meningkatkan aktivitas manajemen reproduksi. Menurut Murray (2009) selang beranak yang baik adalah 12,5 bulan dan dibutuhkan perbaikan apabila selang beranak melebihi 13 bulan.

Service per conception dan lama masa kosong merupakan faktor-faktor yang berhubungan dengan lama selang beranak. Sapi FH pada lokasi penelitian mempunyai lama masa kosong lebih dari 90 hari (97 - 159 hari) akan tetapi mempunyai rataan S/C yang tergolong tinggi yaitu lebih dari 2,0. Akan tetapi dengan pengaturan manajemen yang baik maka lama masa kosong sapi FH pada penelitian ini tidak 
besar pengaruhnya terhadap selang bernak sehingga menyebabkan selang beranak menjadi sama.

\section{SIMPULAN}

Berdasarkan hasil penelitian menunjukkan periode laktasi berpengaruh terhadap performans reproduksi sapi perah FH di PT. Greenfields Indonesia. Semakin tinggi periode laktasi maka semakin tinggi nilai Service per Conception, days open dan calving interval.

\section{DAFTAR PUSTAKA}

Alejandrino, A.L., C.O. Asaad., B. Malabayabas., A.C. De Vera., M.S. Herrera., C.C. Deocaris., L.M. Ignacio and L.P. Palo., 1999. Constraints on dairy cattle productivity at the smallholder level in the Philippines. Preven.Vet. Med. 38: 167-178

Ball, P. J, and Peters, A. R., 2007. Reproduction in Cattle. Ed ke-3. Blackwell Publishing. Oxford United Kingdom.

DeVriest., 2006. Determinants of the cost of days open in dairy cattle. Gainesville 32611. USA. Departemen of Animal Sciences. University of Florida. http://www.animal.ufl.edu/devries/public ations/2006/isv [27 Februari 2017].

Effendi, P., A. Hidayat., A.A. Fuad., Y. Patyadi., K. Taguchi dan T. Sugikawa., 2002. Kesehatan reproduksi. Buku Petunjuk Teknologi Sapi Perah di Indonesia. Bandung : PT. Sony Sugema Pressindo.

Izquierdo, C. A., V. M. X. Campos, C. G. R. Lang, J. A. S. Oaxaca, S. C. Suares, C. A. C. Jimenez, M. S. C. Jimenez, S. D. P. Betancurt, and J. E. G. Liera. 2008. Effect of the offsprings sex on open days in dairy cattle. J. Ani. Vet. Adv. 7: 1329-1331.

Lee, J.K., VanRaden, P.M., Norman, H.D., Wiggans, G.R., Meinert, T.R.. 2008. Relationship of yield during early lactation and days open during current lactation with 305 days yield. J Dairy Sci $80: 771-776$.

Mitchell, R. G., G. W. Rogers, C. D. Dechow, J. E. Vallimont, J. B. Cooper, U. SanderNielsen, and J. S. Clay. 2005. Milk urea nitrogen concentration: heritability and genetic corllation with reproductive performance and disease. J Dairy Sci 88 : $4434-4440$

Murray, B. B., 2009. Maxemazing conception rate in dairy cows : heat detection. Queens Printer for Ontario. http://www.omafra.gov.on.ca/english/live stock/dairy/faacts/84.048.htm Februari 2017].

Oseni, S., Misztal, I., Tsuruta, S and Rekaya, R., 2003. Seasonality of days open in USA Holstein. J Dairy Sci 86 : 3718-3725

Purba., 2008. Gangguan reproduksi sapi perah di PT Greenfield Indonesia, Malang. Direktorat Program Diploma IPB. Bogor

Ray, D.E., A.H. Jassim., D.V. Armstrong., F. Wiersma and J.D. Schuh., 1992. Influence of season and microclimate on fertility of dairy cows in a hot-arid environment. Intl. J. Biomet. 36: 141 145.

Soeharsono., 2008. Laktasi Produksi dan Peranan Air Susu Bagi Kehidupan Manusia. Widya Padjadjaran. Bandung

Steel, R. G. D. dan J. H. Torrie., 2003. Prinsip dan Prosedur Statistik. Suatu Pendekatan Biometrik. Terjemahan : Ir. Bambang Soemantri. Edisi Kedua. PT Gramedia. Jakarta

Sudono, A., Rosdiana, R. F and Setiawan, B.S., 2005. Beternak Sapi Perah Secara Intensif. Ed ke-3. Jakarta: Agromedia Pustaka

Turkylenaz, M. K., 2005. Reproductive characteristic of Holstein cattle reared in a private dairy cattle enterprase in Aydin. Turk J Vet Anim Sci 29: 1049-1052.

Zainudin, M., Ihsan, M.N dan Suyadi., 2015. Efisiensi reproduksi sapi perah $\mathrm{PFH}$ pada berbagai umur di CV. Milkindo Berka Abadi Desa Tegalsari Kecamatan Kepanjen Kabupaten Malang. J. Ilmuilmu Peternakan, 24 (3): 32-37. 